\title{
94. The Occurrence of Spontaneous Polyploid in the Japanese Common Loach, Misgurnus anguicaudatus
}

\author{
By Yoshio OJIma and Akinori TAKaI \\ Department of Biology, Faculty of Science, \\ Kwansei Gakuin University, Nishinomiya \\ (Communicated by Sajiro Makino, M. J. A., Dec. 12, 1979)
}

The loach, Misgurnus anguicaudatus, is a common fresh water teleost having a wide distribution in Japan. They easily breed in captivity, and are largely domesticated in small ponds for food.

Ojima and Hitotsumachi (1969), and Hitotsumachi et al. (1969) reported the chromosomal morphology of this species with some cytophotometric data on the amount of DNA. It was shown that the chromosome number was $2 n=50$ consisting of 7 pairs of meta- and submetacentric type, and 18 pairs of telo- and subtelocentric type.

Recently we had chanced to find unexpectedly the occurrence of polyploid specimens in the Japanese common loaches which were obtained in the market and the field.

Materials and methods. Thirteen individuals were collected from the Chinai river of Shiga prefecture in Japan, and 67 specimens were obtained in the market.

For chromosome study, kidneys were freshly removed, minced with scissors and isolated cells were cultured with MEM for $2 \mathrm{hrs}$. They were treated with colchicine solution at the dosage of $0.5 \mu \mathrm{g} / \mathrm{ml}$ for $2 \mathrm{hrs}$. Following KCl-hypotonization $(0.068 \mathrm{M})$ for $20 \mathrm{~min}$, and Carnoy-fixation as usual, slides were air-dried and Giemsa-stained.

In order to carry out the cytochemical studies on diploid, triploid and tetraploid loaches, liver tissue was fixed with Carnoy's solution, embedded in paraffin, and cut at $8-10 \mu$ in thickness required for microspectrophotometry. DNA amount was estimated in individual nuclei and division figures by Feulgen cytophotometry (Olympus DMSP-1) using the two wave-length method after Ojima and Yamasaki (1968).

Results and remarks. Of the eighty specimens karyotyped, 4 (우3, 今1) were tetraploid with $4 n=100$, while 1 (ㅇ) was triploid with $3 n=75$. The diploid chromosome complement was 50 in number consisting of 5 pairs of metacentrics, 2 pairs of submetacentrics, and 18 pairs of telo- and subtelocentrics (Fig. 1).

A polymorphism was found to occur in the population of diploid 
specimens (Fig. 2). This chromosomal change seemed to be resulted from the Robertsonian fusion. The largest metacentrics was represented by fusion of the third and fourth acrocentrics. This may be due to centric fusion between two acrocentrics leading to a decrease in chromosome number. Although samples here studied were not sufficient for confirmation, this is an indication that this type of interspecific polymorphism might exist in this group.

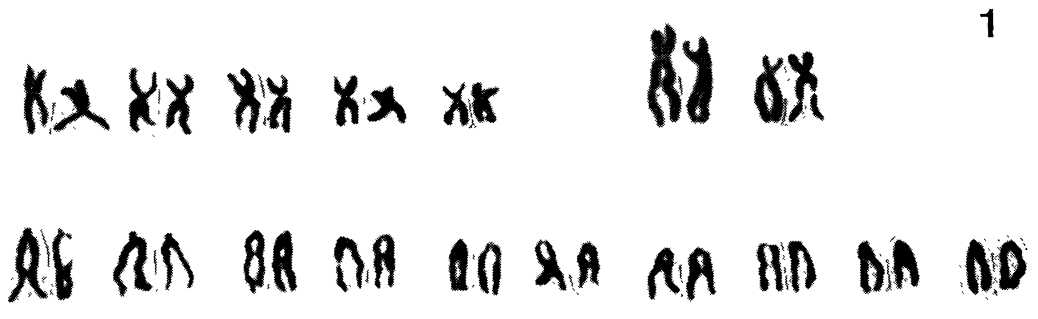

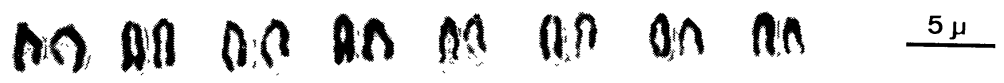

Fig. 1. Serial alignment of somatic chromosomes of Japanese loach, Misgurnus anguicaudatus. Diploid type. $2 n=50(10 \mathrm{M}+4 \mathrm{SM}+36 \mathrm{~T}$, ST).

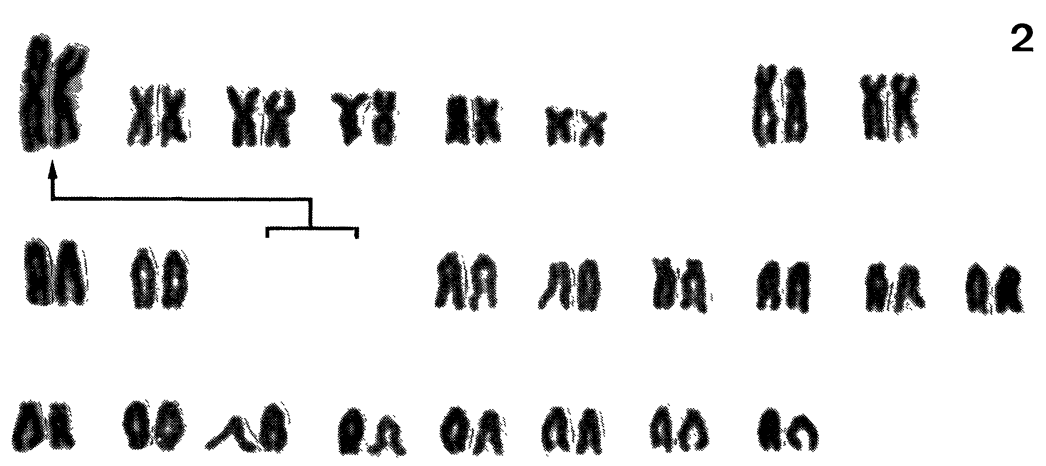

Fig. 2. Showing Robertsonian fusion in the diploid type. $2 n=48(12 \mathrm{M}+4 \mathrm{SM}$ $+32 \mathrm{~T}, \mathrm{ST})$.

Expectedly, the karyotype of triploid individuals was made up from 5 triple metacentrics, 2 triple submetacentrics and 18 triple telo- and subtelocentrics (Fig. 3).

The tetraploid karyotype with 100 chromosomes consisted of 10 pairs of metacentrics, 4 pairs of submetacentrics and 36 pairs of teloand subtelocentrics (Fig. 4).

The results of DNA measurement in individual nuclei of liver cells from the following three types, diploidy, triploidy and tetraploidy, are presented in Fig. 5. On the basis of the DNA data shown 
here, it can be seen that the tetraploid DNA is about twice the diploid value. It can be noted also that the DNA value of triploidy is about intermediate between the diploidy and tetraploidy.

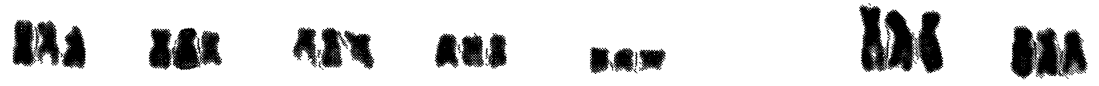

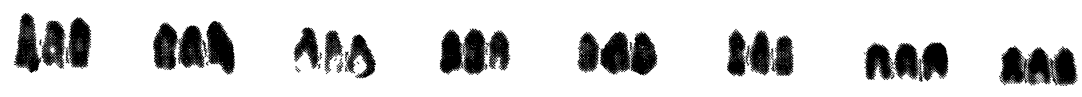

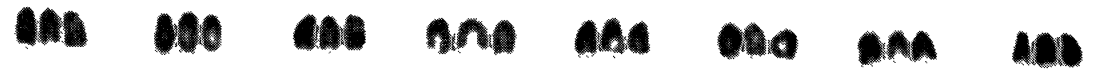
ats

Fig. 3. Showing triploid type. $3 n=75(15 \mathrm{M}+6 \mathrm{SM}+54 \mathrm{~T}$, ST).

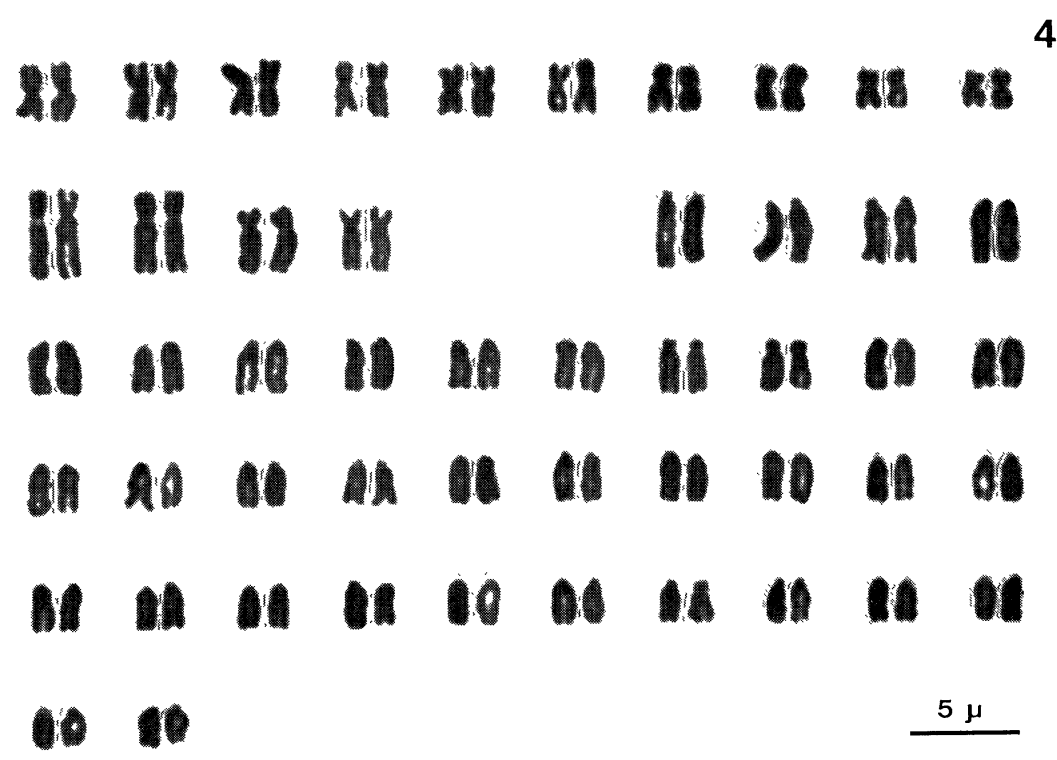

Fig. 4. Showing tetraploid type. $2 n=100(20 \mathrm{M}+8 \mathrm{SM}+72 \mathrm{~T}$, ST).

It has been shown by Hitotsumachi et al. (1969) that four loach species, Misgurnus anguillicaudatus, Barbatula toni, Lefua nikkonis, and Cobitis delicata, were characterized by specific karyotypes distinguishable from one another, in spite of the same number of 50 . Nogusa (1960) reported that one of the Japanese loach, Lefua echigonia, showed 50 chromosomes in diploid. The Khulli loach of south- 
east Asia had also 50 chromosomes (Muramoto et al.). It appears from the above data the fundamental chromosome number of the family Cobitidae is 50, and that there are some structural chromosome components characteristic for each species. Recently, Ueno and Ojima (1976) reported the diploid-tetraploid complexes in the genus Cobitis (Cobitidae, Cyprinida). Namely, Cobitis biwae showed 2 types of the chromosomal forms such as 48 and 96 ; Cobitis taenia taenia had 3 types such as 50, 86 and 94 ; and $C$. taenia strata showed 2 chromosomal types having 50 and 98 chromosomes. This fact will throw a light to analyse the problem regarding that the diploidized tetraploidy becomes endowed with a far greater possibility than its diploid ancestor to sponsor a large evolutional change (Ohno 1974).

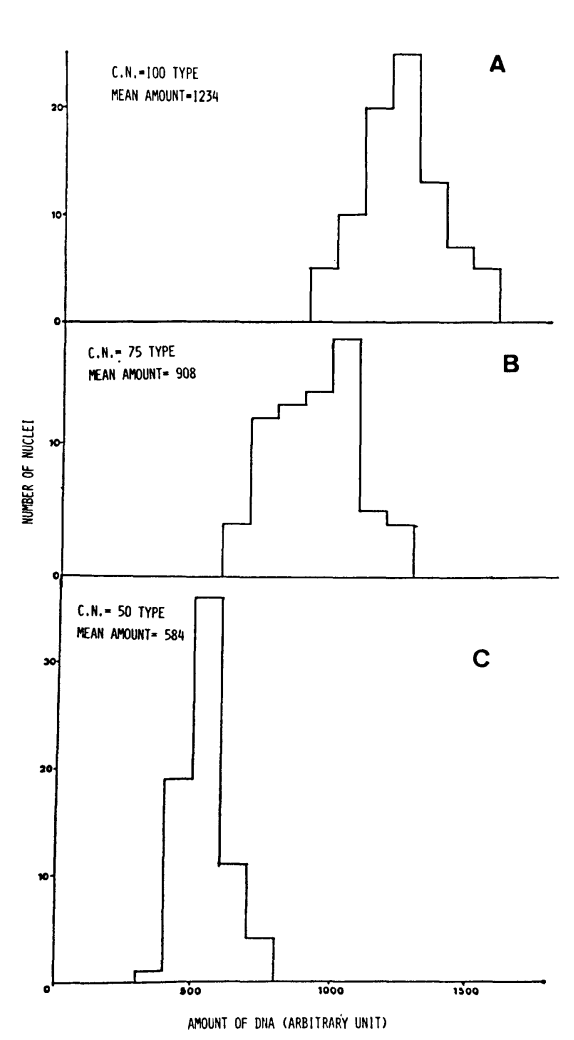

Fig. 5. Histograms showing relative amounts of DNA in liver cells of diploid (A), triploid (B) and tetraploid (C) loach specimens.

Gold (1976) defined a single triploid individual $(3 n=75)$ in the Californian loach, Hesperoleucus symmetricus, that is not associated with a unisexual mode of reproduction and that has not been induced artificially.

Ohno (1974) listed some samples of intraspecific chromosomal 
polymorphism involving Robertsonian fusion which were found in the Pacific northern anchovy (Engraulis mordax), the rainbow trout (Salmo irideus), the European brown trout (Salmo trutta), and the Pacific coho salmo (Oncorhynchus kisutch).

Gosline (1971) classified the teleostean fishes into three larger groups, such as lower, intermediate, and higher groups. Generally speaking, the polyploidy seems to be appeared on the lower group, and the Robertsonian fusion will be found not only in the lower group but also in the intermediate and higher groups. Recently, Ojima and Kashiwagi investigated that the Robertsonian fusion was found among three species in the damsel fish, genus Dascyllus, which is a member of the higher group (unpublished data).

Summary. The triploid and tetraploid specimens of the Japanese common loach, Misgurnus anguillicaudatus, were detected among 13 individuals obtained from the Chinai river of Shiga prefecture and 67 specimens from the market. One polymorphism due to the Robertsonian fusion was found in a population of diploid specimens. The DNA values in individual nuclei of liver cells from diploidy, triploidy and tetraploidy were estimated through the Feulgen cytophotometry (Olympus DMSP-1). The DNA value of tetraploidy was about twice that of diploidy, and that of triploidy was intermediate between diploidy and tetraploidy.

Acknowledgment. We are kindly indebted to Dr. Sajiro Makino, M. J.A., Professor Emeritus, Hokkaido University, for improvement of the manuscript with critical revision of data.

\section{References}

Gold, J. R., and J. C. Avise (1976) : Spontaneous triploidy in the California loach Hesperoleucus symmetricus (Pisces: Cyprinidae). Cytogenet. Cell Genet., 17, 144-149.

Gosline, W. A. (1971) : Functional Morphology and Classification of Teleostean Fishes. Univ. Press of Hawaii.

Hitotsumachi, S., M. Sasaki, and Y. Ojima (1969) : Comparative karyotype study in several species of Japanese loaches (Pisces, Cobitidae). Japan. J. Genet., 44, $157-161$.

Muramoto, J., S. Ohno, and N. B. Atkin (1968) : On the diploid state of the fish order (Ostariopysi). Chromosoma, 24, 59-66.

Nogusa, S. (1960) : A comparative study of the chromosomes in fishes with particular considerations on taxonomy and evolution. Mem. Hyogo Univ. Agric., 3, 1-62.

Ohno, S. (1974) : Animal Cytogenetics, vol. 4, Gebrüder Borntraeger, Berlin.

Ojima, Y., and H. Yamasaki (1968) : Methods of the DNA measurement through the microspectrophotometer. Biophysical Chair, 5, 514-525.

Ojima, Y., and S. Hitotsumachi (1969): Cytogenetical studies in loaches (Pisces, Cobitidae). Japan. Zool. Mag., 78, 139-141.

Ueno, K., and Y. Ojima (1976) : Diploid-tetraploid complexes in the genus Cobitis: (Cobitidae, Cyprinida). Proc. Japan. Acad., 52, 446-449. 